\section{FP1 Results from the Montana Harvest of the Month Pilot and Future for Statewide Program Launch}

Katie Bark, RD, LN, SNS, kbark@mt.gov, Montana State

University, 325 Reid Hall, Bozeman, MT 59717;

Aubree Roth, MS, Montana State University;

Carmen Byker Shanks, PhD

Objective: Evaluate its effectiveness and determine components for the future statewide program. Increase the exposure to and acceptance of locally grown and raised foods of Montana school-aged children through education in classrooms and cafeterias. Increase schools procurement of local, fresh foods.

Description: The Montana Harvest of the Month (HOM) program was created in partnership by Montana Team Nutrition Program, Office of Public Instruction, National Center for Appropriate Technology, Montana FoodCorps, Montana State University Extension, and Gallatin Valley Farm to School. Each month, participating K-12 schools and afterschool programs featured a different Montana food each month in at least one meal or snack, taste test, and an educational activity. This allowed students opportunities to explore Montana foods through engaging learning experiences. HOM materials for 10 foods were developed including classroom, cafeteria, and home handouts, posters, logos, and newsletters. The 10-month pilot was conducted with 12 districts (30 schools), during spring and fall 2015.

Evaluation: The evaluation method included monthly reporting, pre and post student food preference surveys, mid-pilot surveys of site teams, and mid- and post-pilot interviews with team leads. Amount or dollar value of foods purchased was also collected.

Conclusions and Implications: The pilot was largely successful. Program materials were widely accepted and the process worked well in achieving the objectives. Taste test results indicated a majority of the students "liked" or "loved" the HOM foods and the taste test method was well received. The pilot discovered lessons learned for determining the materials and evaluation processes for the statewide launch. Challenges included procurement of locally grown items and completing reports or tracking meals and activities.

Funding: USDA Team Nutrition Training Grant, 2014USDA-TNT-Montana 2014

\section{FP2 Nebraska Team Nutrition (NE TN) Supports Child and Adult Care Food Program (CACFP) Providers' In Implementing CACFP New Meal Pattern}

Christina Burger, MS, cburger2@unl.edu, University of Nebraska, Lincoln, 128 Home Economics, 1650 North 35th Street, Lincoln, NE 68583; Zainab Rida, PhD, RDN, LMNT, Nebraska Department of Education; Dipti Dev, PhD, University of Nebraska, Lincoln; Donnia Behrends, MS, RD, Nebraska Extension; Audre Bedford Hansen, BS, University of Nebraska, Lincoln

\section{USDA Poster Abstracts}

Objective: Expand and enhance Nebraska online training programs that incorporate and implement the 2015 Dietary Guidelines for Americans and CACFP new meal pattern requirements at the childcare facilities. Improve Nebraska childcare provider's nutrition knowledge needed to incorporate CACFP meal pattern changes in 2017.

Description: Childcare providers play an important role in shaping the health of the nation's children. Childcare facilities are in a unique position to support and facilitate healthful eating and promote physical activity for young children, but guidance from food and nutrition professionals is paramount to effectively achieving these outcomes. Four NE TN works with childcare facilities participating in CACFP to provide education and support through innovative training and professional development opportunities. NE TN developed online modules aimed at improving basic nutrition knowledge essential for implementing CACFP new meal pattern changes. Module topics include whole grains, fruit and vegetables, nutrition facts label, meat and meat alternates, dairy, breakfast, snack, infant feeding, and farm to preschool.

Evaluation: A quantitative method was used to assess the nutrition knowledge of child care providers regarding CACFP new meal pattern. Abaselinesurvey was distributed at theannual CACFP regional trainings. A post survey will be completed following the completion of online training modules.

Conclusions and Implications: These online trainings will enable Nebraska Department of Education/Nutrition Services to disseminate training and technical assistance to childcare providers across the state. USDA/Team Nutrition Grants can make a profound difference in addressing the best practices of nutrition and physical activity in early childhood.

Funding: USDA Team Nutrition Training Grant, CNTN16-NE

\section{FP3 Increasing Scratch Cooking in Wisconsin Schools Through Culinary Training}

Alicia Dill, RD, CD, alicia.dill@dpi.wi.gov, Wisconsin Department of Public Instruction, 125 South Webster Street, Madison, WI 53707

Objective: Increase the number of school nutrition professionals incorporating scratch-cooking recipes into menus by providing culinary skills trainings.

Description: In an effort to increase the number of schools utilizing scratch cooking, Wisconsin Team Nutrition developed and offered culinary skills training programs. Throughout the summers of 2013 and 2014, eight regional trainings were hosted. Participants were trained on knife skills, use of seasonings, and time management. Participants learned how to prepare 12 recipes utilizing the newly acquired skills. The Chop! Chop! Culinary Skills training video series was released in 2015. Each video of the six-part series introduces viewers to a specific culinary skill needed for cooking with fresh produce or whole grains. Additionally, viewers are introduced to one or two standardized recipes featuring the introduced culinary skill.

Evaluation: Projects were evaluated through surveys administered upon completion of training and approximately

Continued on page $\$ 126$ 